\title{
TEATRO DE LA MEMORIA: VICTORIA KENT, CLARA CAMPOAMOR Y LAS RAÍCES CORTADAS, DE JERÓNIMO LÓPEZ MOZO
}

\author{
Elena GARCÍA TORRES \\ Universidad de Auckland \\ e.garcia@auckland.ac.nz
}

Resumen: La (re)creación dramática de Clara Campoamor y Victoria Kent en Las raíces cortadas, de Jerónimo López Mozo (2005) revela el entramado ideológico que ha sustentado una visión antagonista de dichos personajes con relación a sus trayectorias vitales, políticas y a sus experiencias del exilio.

Abstract: The (re)creation of Clara Campoamor and Victoria Kent as dramatic personae in Las raíces cortadas by Jerónimo López Mozo (2005) reveals the ideological framework crafted to support their differences with regard to their personal lives, political careers and exiles.

Palabras claves: Clara Campoamor. Victoria Kent. Jerónimo López Mozo. Personaje dramático. Sujeto histórico.

Key Words: Clara Campoamor. Victoria Kent. Jerónimo López Mozo. Dramatic Persona. Historic Subject. 


\section{LAS RAÍCES CORTADAS, DE JERÓNIMO LÓPEZ MOZO: TEATRO DE LA MEMORIA}

Como señala Wilfried Floeck, los textos literarios constituyen un medio privilegiado en la construcción de memorias e identidades colectivas, al tiempo que posibilitan modelos de memoria colectiva alternativos. Semejante potencial emana no sólo de su configuración de los acontecimientos históricos y de los personajes y de su comportamiento, sino también de la estructura de la acción ficticia, de la semantización del espacio y la configuración particular del tiempo (Floeck, 2006: 190-91).

Tal es el caso de Las raíces cortadas, de Jerónimo López Mozo (2005). Efectivamente, en momentos como los actuales, cuando la denominada Memoria Histórica es protagonista de acalorados debates en la vida política y cultural española ${ }^{1}$, dicha obra adquiere especial pertinencia por las reflexiones que concita la (re)creación de sus dos personajes principales: Clara Campoamor y Victoria Kent, figuras políticas enfrentadas por el sufragio femenino durante las Cortes Constituyentes de 1931. La significación de la labor pública de ambas personalidades fue acallada durante la dictadura militar del general Franco, quedando así borradas de la Memoria Histórica española hasta la llegada de la democracia. Es entonces cuando finalmente se reconoció la magnitud de su aportación, así como su relevancia como modelos a seguir para las generaciones de mujeres que las precedieron, tal como señala María Telo Núñez:

Cuando Victoria Kent y la otra diputada en Cortes, Clara Campoamor, triunfaban, yo estudiaba Derecho en la Universidad de Salamanca. Tuvimos mucha suerte las mujeres de la época, suerte de que en momentos tan trascendentales para España, hubiese mujeres preparadas a tan alto nivel como para poder participar en la vida pública. Irradiaban fuerza, transmitían mensajes de poder a las otras mujeres, a las jóvenes que empezábamos a preparar nuestro futuro (1995: 52).

${ }^{1}$ Me refiero a la conocida como Ley de la Memoria Histórica para la extensión de derechos a los afectados por la Guerra Civil y la dictadura, cuyo proyecto fue impulsado por el gobierno socialista de José Luis Rodríguez Zapatero y aprobado en julio de 2006. Entre otras medidas, se incluye el reconocimiento de las víctimas de la Guerra Civil y la apertura de fosas comunes en las que aún yacen los restos de represaliados por los sublevados en la contienda («Zapatero»: sin pág.). Las Cortes Generales dieron el visto bueno definitivo a la ley el 11 de diciembre de 2007 después de que el Pleno del Senado rechazara los vetos presentados por el Partido Popular (PP) y Esquerra Republicana de Catalunya (ERC), junto con las 112 enmiendas que registraron los grupos parlamenarios. De esta manera, la iniciativa ha superado su último trámite en la Cámara Alta, sin que se haya introducido modificación alguna respecto al texto apro- 
Desgraciadamente, pese a la teórica adecuación de la coyuntura actual para su puesta en escena, Las raíces cortadas ha sido tan sólo objeto de una lectura escenificada en el Centro Koldo Michelena Kulturanea de San Sebastián el 20 de mayo de $2005^{2}$. Tan inmerecida suerte no coge de nuevas a su autor. Como todos los pertenecientes a la generación del nuevo teatro español ${ }^{3}$, surgida a mediados de la década de los sesenta, López Mozo apostó en los inicios de su actividad dramática por llevar a cabo una crítica respecto a la situación política española del momento desde una estética vanguardista, en las antípodas del realismo por entonces en boga. Tamaño desafío relegó a la mencionada generación al ostracismo escénico durante el periodo franquista.

El inmerecido confinamiento perduraría paradójicamente con la llegada al país de la democracia, dando de este modo al traste con las esperanzas de dichos autores de ver finalmente fecundar su trabajo. A pesar de un sino tan arbitrario, López Mozo ha obtenido sendos premios teatrales como reconocimiento a su prolija e infatigable labor creadora ${ }^{4}$, fructificada en numerosos textos dramáticos de indiscutible valor cultural ${ }^{5}$. Como acontece con gran parte de los compañeros de generación, los galardones recibidos por López Mozo corroborarían una vez más el sinsentido de ser, en palabras de Alber-

bado el pasado 31 de octubre de 2007 por el Congreso de los Diputados con el voto favorable de todos los grupos, a excepción de los mencionados PP y ERC («Las Cortes Generales»: sin pág).

${ }^{2}$ He de agradecer a López Mozo la generosa información proporcionada, mediante correo electrónico, en la que indica que hubo varias iniciativas para representarla, entre las que se encuentra el intento infructuoso de Juan Antonio Hormigón hace dos años. En la actualidad hay en marcha varios proyectos: la compañía Trotea quiere representarla en 2008 y la actriz uruguaya Marta Laino lo hará también en 2008 en Montevideo. Por su parte, Les Éditions de l'Amandier prepara su publicación en París con el título de Les racines coupés, en traducción de David Ferré, poseyendo los derechos de representación en Francia la hispanista Irene Sadowoska.

3 Como informa José Romera Castillo (2000: 10), además de la etiqueta de nuevo teatro español, este grupo de autores ha recibido además entre otras denominaciones las de: «underground» $\mathrm{o}$ «subterráneo» (George E. Wellewarth), «silenciado» (L. Teresa Valdivieso), «generación simbolista» (José Rubial) «marginado», «soterrado», «inconformista»y «jóvenes autores»).

4 López Mozo fue Premio Nacional de Literatura Dramática 1998, habiendo sido finalista en los años 1991 y 1995. Además, a lo largo de su carrera ha ido acumulando, entre otros, los siguientes premios: Sitges de Teatro 1967; Nacional de Teatro para Autores Universitarios 1968; Arniches 1970, 1979 y 2000, del Ayuntamiento de Alicante; Castilla-La Mancha de Teatro 1986; Enrique Llovet 1988, de la Diputación de Málaga; Hermanos Machado 1992, del Ayuntamiento de Sevilla; Álvarez Quintero 1992, de la Real Academia Española; Tirso de Molina 1996; Fray Luis de León 1998; Serantes 2000, del Ayuntamiento de Santurzi; ACE (Association of Latin Entertainment Critics of New York) 2001 y Ciudad de San Sebastián 2002 (Cf. Romera Castillo, 2000).

5 Para acceder a una exhaustiva recopilación de la trayectoria dramática de López Mozo, desde sus inicios en 1964 hasta 1997, véase el prólogo de Romera Castillo a la edición de las obras «Combate de ciegos» $\mathrm{y}$ «Yo maldita india...». 
to Miralles, «la generación más premiada y menos representada». Al analizar las causas de las mencionadas dificultades para su proyección dramática, López Mozo coincide con Miralles en calificar la marginación sufrida por el nuevo teatro español de «genocidio cultural», provocado por la decisión de los padres de la transición política de cimentar el presente sobre la amnesia colectiva. En opinión de ambos autores, se trataría de borrar de la historia no sólo el franquismo, sino también el antifranquismo (1999b: 17).

Es por ello que con una democracia ya consolidada resulte de nuevo desafortunadamente irónico el aplazamiento de la representación de una obra como Las raíces cortadas, auténtico alegato contra la amnesia colectiva desde su apelación a la memoria histórica ${ }^{6}$. A la espera que Las raíces cortadas consiga su culminación en virtud de su puesta en escena, nos queda el recurso de acceder a la obra mediante su formato impreso. Éste atestigua el indiscutible valor cultural de un texto surgido como resultado de una invitación a escribir una obra protagonizada por mujeres. Según revela López Mozo en la introducción, el proyecto se concibió asimismo supeditado a determinadas condiciones: «[Q]ue la puesta en escena no fuera complicada ni el reparto extenso, todo ello en aras de que la producción no resultara excesivamente costosa» $(2005: 15)^{7}$.

A partir de las confidencias expuestas, las cuarenta páginas de que consta la introducción servirán a López Mozo no sólo como una plataforma para explicitar el entramado de la obra — «los mimbres que he utilizado para construir la obra que sigue» (2005: 40)—, sino también para proporcionar al lector un breve ensayo concerniente a las vidas y circunstancias de sus protagonistas, resultando así una excelente sinopsis histórica de los hechos acaecidos. Se genera así una interacción textual entre dos géneros: el ensayo y la

${ }^{6}$ No será la primera vez que el teatro de López Mozo hace de la historia su protagonista. Además de la obra objeto del presente estudio, entre otros títulos de la dilatada andadura teatral del autor que bucean en el pasado cabe mencionar: Guernica (1969), Anarchia 36 (1971), El Fernando (1972, en colaboración con varios autores), Comedia de la olla romana en que cuece su arte la Lozana (1977), Como reses (1980, en colaboración con Luis Matilla), Yo, maldita india... (1988) y La Infanta de Velázquez (1999).

7 Según información del propio autor mediante correo electrónico, la idea de escribir Las raíces cortadas fue consecuencia de una reunión con Antonio Malonda y Yolanda Monreal, directores de escena y profesores de arte dramático, con quienes López Mozo había ya trabajado en sucesivas ocasiones: su primer trabajo en común fue en 1977 con Comedia de la olla romana en que cuece su arte la lozana, en la que Malonda fue adjunto a la dirección y Monreal trabajó como actriz. Otras colaboraciones incluyen Como reses (1987), Yo, maldita india (1988), Tartufo (versión libre de la obra de Molière, 1994), Haciendo memoria (1997), Eloídes (1999), Los ojos de Edipo (2000), Madrid-París (Lectura, 2003) y El escritor y su biógrafo (Lectura escenificada, 2004). Desgraciadamente, por una serie de circunstancias), Las raíces cortadas no pudo llegar a representarse. 
obra teatral, cuyo resultado produce una fusión entre la «realidad» histórica y la «realidad» dramática. De ahí que quepa calificar la lectura de la versión impresa de Las raíces cortadas como un ejercicio «transgenérico», en cuanto que implica una simbiosis textual que aúna la versión histórica («real») y la dramática («ficticia»).

\section{SEMBLANZAS DE VICTORIA KENT Y CLARA CAMPOAMOR EN CLAVE DIALÉCTICA Y ANTAGÓNICA}

A partir de dicha hibridación, se analiza en el presente artículo la dinámica que surge de la conjunción entre sujeto histórico y personaje dramático, abordando la interacción del componente histórico con la (re)creación de la condición humana de las protagonistas. Como nos advierte López Mozo, tras la determinación del tema, surgió el desafío de su escasa dimensión teatral. Sin dejar de lado el asunto del voto femenino, el dramaturgo necesitaba enriquecer su visión de los personajes para crearlos con un perfil más claro y poder dotar a la obra de una sustancia dramática más consistente. Queda así manifiesta la preocupación de López Mozo por captar el interés del espectador, razón que aduce para supeditar el tema de Las raíces a una reflexión dialéctica de los hechos desde una perspectiva contemporánea. Como comenta al respecto el autor: «[A]l pie forzado del voto femenino como tema de mi obra, añadí el del exilio, porque creía que era más interesante para el espectador actual, al tiempo que, desde el punto de vista dramático, tenía mayor atractivo» $(2005: 30)$.

A fin de sondear en la personalidad de sus personajes, emprendió una labor de investigación, la cual le desveló aspectos interesantes de sus trayectorias vitales que le resultaron de permanente actualidad. Es esta búsqueda de una mejor ponderación actual de la significación histórica de las protagonistas de la obra lo que lleva a López Mozo a recrearlas desde su infancia a su fallecimiento, resaltando así su dimensión temporal como personajes históricos y dramáticos.

Con tal propósito, la relación entre ambos personajes aparece representada en la obra en clave antagónica y articulada mediante la dicotomía público-privado. Para ello, la exhaustiva recopilación de datos biográficos de la introducción queda imbricada en el drama de los avatares personales de ambas mujeres. Será a través de cinco encuentros apócrifos donde se hurga en los laberintos de sus conciencias en pos de una ponderación de sus tra- 
yectorias políticas y vitales ${ }^{8}$. Se va tejiendo a lo largo de la obra el drama de dos vidas subyugadas al contexto sociopolítico de la época. Ahí radica la apelación a la memoria histórica reclamada en la obra, a través de la tensión que aflora en sus (des)encuentros. Emerge entonces el entramado ideológico que los sustenta, al tiempo que se contrarrestan las versiones oficiales sobre ambas figuras políticas.

Puesto que las dos protagonistas de Las raíces cortadas no son producto de la ficción, sino de la realidad histórica, un condicionante a tener en cuenta para su construcción como personajes dramáticos es que el autor hubo de contar con los límites creativos impuestos por una biografía concreta en unas circunstancias determinadas. Tal restricción no habría de ir necesariamente en detrimento ni de la caracterización de los personajes, ni de la acción dramática. Ciertamente, en toda obra teatral la ineludible e inextricable relación entre personaje y acción dramática se manifiesta a lo largo de la trama mediante una superposición de la que se nutren ambos elementos dramáticos, puesto que todo comportamiento responde a una serie de circunstancias acumuladas. La individualidad del personaje se conforma y adquiere relevancia en virtud de la acción dramática, al proporcionar ésta información sobre aquél; inversamente, cuanto mayor es la caracterización del personaje, la acción deviene más compleja y consigue mayor intensidad dramática.

En Las raíces cortadas, los límites a los que se ve circunscrito el registro de los personajes históricos no impidió a López Mozo llevar a cabo un proceso parecido al que acostumbra a seguir con cualquier personaje dramático. Tal como informa el autor:

Al principio del proceso creativo siempre elaboro las biografías de los personajes, aunque en la obra sólo ofrezca algunos fragmentos. Esas biografías son una especie de herramienta. En el caso de que los personajes sean históricos, el trabajo de investigación es más sencillo, pues se trata de recurrir a los datos conocidos sobre ellos. A veces, se complica algo, sobre todo cuando quieres conocer detalles que corresponden a sus vidas privadas, por lo general poco difundidos. Pero con paciencia y algo de suerte acabas entrando en esa parcela más íntima, de escaso interés documental, pero muy importante para quien construye el personaje, para hacerle más humano (Campal 2007: sin pág.).

${ }^{8}$ De los cinco encuentros que tienen lugar en la obra, sólo el segundo, en la parte correspondiente al debate parlamentario sobre el sufragio femenino, aconteció en la realidad. 
La mencionada necesidad de conjugar la dimensión histórica de los personajes con su aspecto personal le lleva a López Mozo a exponer en la introducción con atino y precisión las biografías y circunstancias históricas de las protagonistas. A partir de la documentación recopilada, el lector asiste a cómo la obra (re)creará determinados momentos de las vidas de ambas mujeres. Su dimensión histórica está siempre presente, si bien aparece subordinada a las necesidades dramáticas del texto.

Estructurada en cuatro actos, la obra muestra los entresijos de las motivaciones, inquietudes y pareceres de las protagonistas. Engarzadas en diálogos austeros, las palabras, a modo minimalista, permitirán tal indagación ${ }^{9}$, la cual no se presenta de modo lineal, sino mediante continuos saltos hacia delante y hacia atrás. El juego cronológico adquiere así un carácter circular, en el que aparece resaltada su relatividad. Tal énfasis permite al texto alcanzar toda su expresión dramática, puesto que el mosaico temporal trazado dota a sus piezas de una versatilidad semántica susceptible de sucesivos niveles de significación. Emerge entonces un primer nivel de significación que pasaremos a analizar. Éste viene constituido por la semblanza de sus dos protagonistas, estructurada en clave dialécticamente antagónica a partir de sus aspiraciones profesionales, sus trayectorias políticas y sus experiencias del exilio. Es en virtud de dicha dialéctica que las realidades de género y de clase social muestran su importancia a la hora de interpretar el itinerario vital y político de Campoamor y Kent.

\subsection{Aspiraciones profesionales}

Al inicio de la obra, durante el primer encuentro de las protagonistas, asistimos a cómo las niñas Clara y Victoria elucubran qué serán de mayor. En el diálogo que resume sus años de formación, el talante pionero y ambicioso de estas «amazonas del espíritu» (Mangini, 2001: 233) expresa el ideal al que aspiran. Si Kent quiere ser Concepción Arenal (45), Campoamor, tras declarar que se ocupará de mejorar las condiciones de las mujeres, afirmará: «Cuando sea mayor, lo que de verdad quiero ser es una mujer de pelo en pecho» (2005: 47). Tamaña afirmación recoge irónicamente la clarividencia de Campoamor con respecto a la situación de la mujer en su tiempo, al expresar el impacto de los arquetipos tradicionales de género.

9 Se manifiesta así la convicción de López Mozo sobre la idoneidad de la palabra para dicho cometido: «[P]ara profundizar en el conocimiento del ser humano, y ése es uno de los cometidos del teatro, es imprescindible la palabra» (1999a: 37). 
En efecto, en su lucha por transformar y cambiar tal realidad, Campoamor es consciente de la creencia de la época de la imposibilidad de las mujeres para convertirse en protagonistas de la historia. Por ello, desde su condición de mujer, recurre lingüísticamente a expresar su deseo de luchar denodadamente por mejorar la situación de las mujeres a partir del ideal masculino de hombre aguerrido: «un hombre de pelo en pecho». Se recogería así en la obra la falta de un orden simbólico en el que las mujeres se reconozcan, requisito sine qua non para tener acceso a la sociedad y a la cultura. Tal carencia ha sido insistentemente reclamada por Luce Irigaray, en su lectura del concepto lacaniano de relación especular entre el ser humano y el lenguaje. Irigaray considera que, dado que el lenguaje funciona como un espejo y el falogocentrismo late en el centro mismo de él, el mundo como representación es una proyección del sujeto masculino (1985: 159). Como señala Mary Nash, el repertorio cultural del discurso de género, la retórica y el lenguaje de las imágenes son mecanismos importantes de control social que refuerzan los modelos de género (1999: 33).

Otro aspecto que se colige de contrastar las percepciones futuras de las niñas Campoamor y Kent son las diferencias socioeconómicas de sus orígenes, lo que no impide a ambas personalidades mostrar el carácter ambicioso de sus proyectos. Como resalta Shirley Mangini, «si bien la trayectoria de Kent puede resultar lógica dado su ambiente familiar y profesional, Campoamor nos ofrece un cuadro mucho más sorprendente, pues carecía de una formación convencional y de los medios económicos necesarios para llegar al nivel profesional que alcanzó» (2001: 214). Efectivamente, la pertenencia a una familia de clase media con una holgada situación económica, le permite en la obra a la niña Victoria responder con rotundidad: «Lo que se me antoje» (2005: 44), ante la pregunta de la niña Clara sobre qué quiere ser de mayor. Kent prosigue expresando su desagrado por el colegio de monjas al que asiste, para declarar su voluntad de seguir formándose en su casa con profesores particulares. Anuncia que posteriormente irá a una residencia de señoritas muy importante en Madrid, donde estudiará derecho, para poder servir a la justicia y a España. Ciertamente, Victoria Kent Siano nació en Málaga en 1892, en el seno de una familia de clase media acomodada y liberal. En dicha ciudad cursó la enseñanza elemental en casa y estudios de grado medio en la Escuela Normal de Maestras (Capel Martínez, 1992: 156; Telo Núñez, 1995: 54). En 1917 se trasladó a Madrid, donde realizó el Bachillerato y los estudios de derecho. Allí se instalaría en la Residencia de Estudiantes para señoritas, dirigida por María de Maeztu y vinculada a la Institución Libre de Enseñanza, constituyéndose, de hecho, en su primera residente (Mangini, 2001: 83). 
Por su parte, las ambiciones de Campoamor reflejan su conciencia de las limitaciones socioeconómicas a las que se enfrenta: tras indicar su preferencia por la profesión de su madre (costurera), frente a la de su abuela (portera), se decanta por ser primero dependienta y después telegrafista, en concreto funcionaria del Cuerpo de Correos y Telégrafos. Además, quiere trabajar en un periódico, como su padre, aprender francés y traducir novelas. Se ve estudiando posteriormente: el bachillerato primero y luego derecho en la universidad. Una vez licenciada, que calcula sea a los treinta y seis años de edad, será tan buena abogada que le será otorgada la Gran Cruz del Rey, a la que predice renunciará, porque para entonces será republicana.

Estas premoniciones cumplidas anuncian en la obra la realidad del sujeto histórico. Clara Campoamor Rodríguez, madrileña nacida en 1888 fue, en palabras de Neus Samblancat Miranda, «una mujer hecha a sí misma»: sus orígenes humildes y la temprana muerte de su padre, quien falleció contando ella tres años de edad, la obligaron a trabajar desde muy joven, primero como modista y luego como dependienta. Ingresó en 1909 como funcionaria en el Cuerpo de Correos y Telégrafos, sacando de nuevo unas oposiciones con el número uno como profesora de mecanografía en la Escuela de Adultas. Asistió en cuestiones secretariales al periódico La Tribuna y en sus ratos libres tradujo del francés para la editorial Calpe ${ }^{10}$. Paliadas en alguna medida las circunstancias económicas familiares, Campoamor reinició sus estudios: obtuvo el título de bachiller en 1923 y en diciembre de 1924, en menos de dos años, se licenció en Derecho por la Universidad Central de Madrid (2002: 19-23).

\subsection{Trayectorias políticas}

Ya en el primer encuentro que acontece en Las raíces cortadas aparecen indicios de las futuras carreras políticas de las protagonistas. El camino trazado en la representación por Kent para llegar a «ser Concepción Arenal» (2005: 45) muestra una trayectoria decididamente meteórica, carente de desviaciones. Como observa Telo Núñez, políticamente hablando, Kent fue

${ }^{10}$ Concha Fagoaga y Paloma Saavedra observan cómo los trabajos de profesora de la Escuela de Adultas de Madrid y de secretaria en el periódico La Tribuna, resultaron decisivos para la formación política de Campoamor: «La agitación política de la época, vivida día a día entre los redactores del periódico y el contacto directo con la cuestión de la mujer a través de su participación educadora en la Escuela de Adultas iban a ser dos determinantes que la llevan a replantearse su propia formación y exigirse a sí misma una preparación intelectual mínima indispensable para entrar en contacto con la vida pública» (1981: 29). 
una «mujer de partido» (1995: 57). Perteneció al Radical Socialista desde su fundación, y por él presentó su candidatura a diputada en Cortes los años 1931 y 1933, sin lograr salir reelegida en las elecciones de este último año. Formó parte de la Asamblea Constituyente para la fusión del partido Radical Socialista con Acción Republicana, el 2 de abril de 1934, denominándose Izquierda Republicana, y su fidelidad, tanto antes como después de la misma, fue manifiesta.

En el caso de Campoamor, su carrera política se forjó mediante diversas adscripciones. Tras haber pertenecido en 1929 al comité organizador de la Agrupación Liberal Socialista, Campoamor militó en Acción Republicana, llegando incluso a ser elegida en mayo de 1931 miembro del Consejo Nacional. Sin embargo, optaría por el Partido Radical de Alejandro Lerroux para presentarse como diputada para las Cortes Constituyentes de la Segunda República en las elecciones de 1931 y de 1933, sin lograr en estas últimas revalidar su escaño, como asimismo aconteció a Kent. En 1935 abandonaría dicho partido, comunicando a Lerroux, mediante una carta ampliamente difundida en la prensa de la época, su desacuerdo con la política realizada en la labor gubernamental de los radicales. En su intento de encontrar acomodo en otro partido, Campoamor hubo de enfrentarse ese mismo año al rechazo de su ingreso en las filas de Izquierda Republicana. Según Samblancat Miranda, «antiguos resabios políticos le hacen pagar ahora su anterior abandono de Acción Republicana» (2002: 38). La negativa de Izquierda Republicana supuso un duro golpe para Campoamor, intensificado meses más tarde por una nueva sensación de derrota: se le niega su solicitud de acta para inscribirse en el Frente Popular representando a Unión Republicana Femenina, agrupación que ella misma había fundado en 1931 «para laborar contra el ambiente adverso que existía respecto a la concesión del voto femenino» (Capel Martínez, 1992: 152).

Sin embargo, no sería lícito tildar a Campoamor de inconsecuente. Bien al contrario, su carrera política exhumó coherencia, enfocándose desde el inicio en una lucha denodada por defender los derechos de las mujeres. Tristemente, pese a lograr con éxito tal objetivo, al conseguir sacar adelante en la Cámara la aprobación del voto femenino y colaborar decisivamente en la elaboración de la ley del divorcio, tal triunfo se convertiría en su «pecado mortal» ${ }^{11}$, el cual habría de purgar a costa de su carrera política. Efectivamente,

11 Mi pecado mortal: El voto femenino y yo sería el revelador título de la obra que Campoamor (1981) escribió en 1936 como respuesta a sus detractores, por las críticas y las consecuencias negativas en su actividad política que le acarreó su defensa del voto femenino. 
como observa Samblancat Miranda, el logro parlamentario de Campoamor al conseguir la aprobación del sufragio femenino constituye paradójicamente «el inicio de su declive» (2000: 124), consecuencia indudable de su lucidez en unas Cortes tildadas por la misma Campoamor de «radicalismo laríngeo» (1981: 175). Al respecto añadiría Campoamor sarcásticamente: «El voto femenino fue, a partir de 1933, la lejía de mejor marca para lavar torpezas políticas varoniles. Si pasados por ella los políticos de izquierda no han quedado más resplandecientes e impolutos culpa será del tejido» (1981: 248).

El «precio» político que hubo de pagar Campoamor por su aportación constitucional será motivo de reflexión en Las raíces cortadas, a partir de las divergencias de las protagonistas a la hora de juzgar los hechos, enfatizadas por los distintos efectos que el tiempo ha causado en ambas. La excusa teatral para llevar a cabo tal proceso catártico, será el anuncio de la muerte de Campoamor, al inicio del segundo encuentro. Corre el año 1973. Desde la redacción de la revista Ibérica en Nueva York a finales de abril, Kent recibe la noticia telefónicamente a través de una periodista, a quien le interesa indagar sobre la relación entre las dos mujeres, aludiendo al debate parlamentario sobre el voto femenino del 31 y a sus discrepancias de entonces ${ }^{12}$. Kent equipara el debate con «una extraña batalla librada en escenarios lejanos» y con «una obra representada entre bastidores por y para la burguesía, de espaldas a la realidad de España» (2005: 50). Por lo tanto, al destacar no sólo la naturaleza beligerante y teatral del debate, sino también el carácter elitista de la representación, la percepción de personaje dramático de Kent del mencionado debate, desde su condición de exiliada durante más de treinta y tres años, expresa su carencia de sentido.

El balance crítico desde el presente de los hechos pasados cobra mayor relieve al retrotraerse la representación en ese punto a la época de diputadas de las protagonistas. Sus diferentes pareceres con respecto al derecho al sufragio de la mujer, correspondiente al artículo 34 del Proyecto de Constitución, se dramatizarán en un diálogo que entablarían previo al debate parlamentario del 1 de octubre de 1931. En él, se reproducen gran parte de los argumentos esgrimidos por ambas políticas: la decidida defensa de Campoamor, basada en la obligación de la República de satisfacer un derecho fundamental e inalienable del que hasta el momento sólo disfrutaban los hom-

${ }^{12}$ La revista Ibérica, publicación dirigida por Kent con carácter mensual en inglés y español, nació en Nueva York en 1954 y pervivió durante veinte años más, con el propósito de difundir los valores de la República y de luchar contra la dictadura de Franco (Villena, 2007: 207). 
bres, frente a las reticencias de Kent a su concesión, basadas en el hipotético peligro que el voto femenino, supuestamente susceptible de manipulación por el clero, pudiera suponer para la joven República. Como observa Zenaida Gutiérrez Vega: «Las consideraciones de Victoria eran de tipo práctico y respondían "a los intereses generales del país"; las de Clara Campoamor, a un principio teórico de igualdad, "un problema de ética, de pura ética reconocer a la mujer, ser humano, todos sus derechos"» (2001: 74).

Telo Núñez alega que si el partido de Kent, el Radical Socialista, «hubiese enarbolado la bandera del voto a la mujer, ella lo hubiese defendido con gusto» (1995: 74). No obstante, Kent no hubo de plegarse a una disciplina de partido en su voto sobre el sufragio femenino ya que, según informa Miguel Ángel Villena, la controversia política y social que comportó el tema del sufragio femenino generó profundas discrepancias en el seno de la mayoría republicano-socialista, hasta el punto de que los partidos optaron por conceder libertad de voto a sus parlamentarios (2007: 107). Tal polémica se vio agudizada no sólo por la libertad de voto en los partidos, sino también por la diferencia de posiciones que asumieron las dos únicas diputadas de la Cámara en ese momento ${ }^{13}$.

Las bromas de talante sexista en torno a la incapacidad de las mujeres en ponerse de acuerdo inundaron los pasillos del Congreso, las tertulias y los mercados (Villena, 2007: 110). Es más, la repercusión del debate tuvo un fuerte reflejo en los medios de la época, enfatizándose la pugna entre Kent y Campoamor. Así queda de manifiesto en la caricatura realizada por Adalberto para la popular revista Gracia y Justicia, en la que aparece Campoamor, henchida de júbilo, espetando a su derrotada «oponente», sudorosa y tendida en el suelo: «¿Y a mí Kent?». Igualmente, Ferrer del diario La Voz, presentó fotografías de las cabezas de las diputadas con el cuerpo de deportistas de esgrima (Villena, 2007: 110). El mismo presidente de la República calificaría en sus memorias el enfrentamiento verbal de las dos diputadas de «muy divertido» (1978: 199) ${ }^{14}$. Pese a que finalmente se aprobaría la concesión del voto

13 Margarita Nelken, la tercera diputada femenina de las primeras Cortes Constituyentes del 31, lograría su escaño finalmente unas semanas después (Fagoaga, 1985: 188).

${ }^{14}$ Con respecto a las opiniones de Manuel Azaña sobre Campoamor y Kent son dos las citas que les dedica en sus memorias. La primera se refiere al día del debate parlamentario. Por entonces él era el líder de Acción Republicana y diputado en Cortes. Tras calificar el ambiente de «mucho griterío», añade: «[C]ombate oratorio entre la señorita Kent y la señorita Campoamor. Muy divertido... La Campoamor es más lista y más elocuente que la Kent, pero también más antipática. La Kent habla para su canesú, y acciona con la diestra sacudiendo el aire con giros violentos y cerrando el puño como si cazara moscas al vuelo» (1978: 199). La segunda mención tiene lugar con motivo del cese de Kent de su cargo de Directora 
femenino por 161 votos a favor y 121 en contra, Las raíces hace hincapié en cómo se exacerbó con sarcasmo el desacuerdo de las diputadas. Así, una voz anónima comenta con sorna: «Dos mujeres en la Cámara y ni por casualidad se ponen de acuerdo. ¿Qué pasará cuando sean cincuenta las que actúen?» (2005: 60). Tal intervención reproduce literalmente dos comentarios antifeministas jocosos sobre tan trascendente hecho histórico que aparecieron en diferentes periódicos de la época (Gutiérrez Vega, 2001: 76).

Kent estaba convencida de que con la concesión del voto femenino en aquel momento se arriesgaba el futuro de la República. De ahí que acuse a Campoamor de utilizar la «demagogia» (2005: 56) para la consecución de sus fines, amén de servir a los intereses de la derecha (2005: 58). Sin embargo, desde la perspectiva actual la postura de Kent ha sido criticada, especialmente desde círculos feministas. En este sentido, Carmen Alborch la califica de paternalista y elitista, ya que su consideración de las mujeres como menores de edad, guiada por razones de pragmatismo político y clasismo intelectual, implica haber interiorizado los roles masculinos (2007: 24). Apoyaría tal observación Villena, al observar que Kent desplegó «un discurso en gran medida varonil que revelaba que era una mujer que había logrado triunfar en un mundo de hombres» (2007: 108). Se evidencia de nuevo el sometimiento de las mujeres de la época a una representación según parámetros masculinos exclusivamente. Por su parte, Nash señala que en 1931 seguía existiendo una lectura de la subjetividad política y de la ciudadanía desde una perspectiva de género, tanto en la derecha como en la izquierda. Así, los argumentos de Kent en contra de la conveniencia política de conceder el voto a las mujeres por su supuesta alineación política con las fuerzas conservadoras se fundaban en la clásica premisa de la dependencia femenina. En este caso, la ausencia de subjetividad política autónoma se basaba en el doble supuesto de la autoridad masculina en el seno de la familia - la mujer votaría lo que dijera el marido o el padre - y la autoridad religiosa: la mujer votaría al dictado de los sacerdotes (1999: 80).

\subsection{Experiencias del exilio}

Las divergentes experiencias del exilio de las dos protagonistas de Las raíces cortadas constituyen otro punto de fricción entre ellas. No sólo

General de Prisiones: «Victoria es generalmente sencilla y agradable, y la única de las tres señoras parlamentarias simpática; creo que es la única...correcta» (1978: 469). 
afrontaron el exilio con actitudes diferentes, sino que su separación física de España se inició por causas y en momentos diversos. La partida al exilio de Campoamor aparece en la obra durante el tercer encuentro de las protagonistas, el cual supuestamente tendría lugar en 1936, un mes después de estallar la Guerra Civil. Campoamor sale de su casa para abandonar Madrid y fortuitamente se encuentra con Kent, quien le pregunta por la causa de su marcha. Campoamor confiesa no sentirse segura, ya que hace unos días unos desconocidos han preguntado al portero por ella (2005: 66). Kent reprocha a Campoamor lo precipitado de su abandono (2005: 66), llegándolo a calificar de «espantada de la que deberá rendir cuentas algún día» (2005: 68). Campoamor se defiende alegando: «El ambiente que se respira no me gusta. Los fanatismos de uno y otro lado me revuelven las tripas» (2005: 66).

De nuevo, las protagonistas se enzarzarán en una discusión sobre dos formas divergentes de analizar lo que está pasando. La actuación de Campoamor con respecto al voto femenino volverá a ser utilizada por Kent como chivo expiatorio del colapso de la República (2005: 67). A propósito del fracasado intento de Campoamor por entrar en Izquierda Republicana tras su salida del partido Radical, Campoamor le recuerda con sarcasmo a Kent su falta de apoyo: «Te honra que no te refugiaste en el anonimato, como otros. Bien en alto llevabas la bola negra para que todos vieran que votabas contra la Campoamor» (2005: 68). No obstante, Gutiérrez Vega declara erróneos los rumores de que Kent se opusiera a la entrada de Campoamor en Izquierda Republicana y considera que la oposición, según le confesara la propia Kent, acaso se debieran a sus viejas rencillas con Azaña (2001: 82). De cualquier manera, en la obra, Kent justifica su oposición descalificando la trayectoria política de Campoamor, a la que tilda de «errática», «oportunista» y «trepadora descarada» (2005: 68). Campoamor aduce en su defensa que jamás ha hipotecado sus ideas, ya que el único interés que le ha guiado ha sido el de servir el interés público (2005: 68).

Las constantes reconvenciones de Kent a Campoamor reflejan cómo esta última sufrió el rechazo y los reproches de ambos bandos de la Guerra Civil. En este sentido, considero que la postura de Campoamor con respecto a su falta de toma de partido, sin que le resultara óbice para padecer el exilio, la convierte en parte de esa tercera España cuya existencia sostiene Paul Preston. Para el historiador, «en realidad existían tres Españas más que dos bandos antagónicos» (2003: 15). Alega que la tercera España estaría constituida por aquellas personas que se negaron a tomar parte en la guerra, si bien sufrieron por el extremismo de un bando o de ambos (2003: 
16) ${ }^{15}$. Tal fue el caso de Campoamor. Sus padecimientos a manos de los de la izquierda y de los de la derecha, a causa de su moderación, la convierten en una palmaria exponente de la categoría de la tercera España. Pese a declarar que sus ideas están en el campo de la izquierda (2005: 68), la falta de adherencias políticas de Campoamor queda repetidamente resaltada en la obra: «Me repugnan los excesos y en las revoluciones hay demasiados» (2005: 74) y «Aquella República estaba herida de muerte y, con ella, la democracia. Al final, ganara quien ganara, tenía que venir, por fuerza, una dictadura» (2005: 76). No obstante, cabe señalar, tal como apostilla Preston, que el hecho de pertenecer a la tercera España no implica que sus componentes «fuesen de alguna manera moralmente superiores a los que sirvieron con lealtad a ambos lados» (2003: 22).

Los reproches mutuos entre las protagonistas de la obra seguirán arreciando cuando comentan en su cuarto encuentro sus experiencias como exiliadas: las vicisitudes de Kent en la Francia colaboracionista y la larga estancia de Campoamor en Argentina, la cual hubo de abandonar muy a su pesar con la llegada del General Perón. Ante la recriminación de Kent a Campoamor por su aislamiento y su falta de contacto con otros exiliados españoles, ésta confiesa que se propuso olvidar el pasado (2005: 75). También se traen a colación sus dos intentos fallidos de regresar a España. Frente a la amargura del exilio de Campoamor, el de Kent carece de ella. Es más, incluso llega a confesar: «Casi me da vergüenza decir que, a pesar de todo, mi exilio ha sido afortunado... He conocido a gentes magníficas, he hecho buenos amigos, he dado con una persona maravillosa que ha transformado mi vida ...» (2005: 79).

Se refleja así en la obra la información que proporciona la introducción sobre los exilios de ambas políticas: «Los exilios de Clara Campoamor y Victoria Kent fueron muy diferentes. Mientras para la primera fue un amargo trago que nunca digirió, para la segunda, dedicada a la política y relacionada con importantes personalidades de ese sector y del mundo intelectual, estuvo lleno de contenido» (2005: 39). Efectivamente, el desgarrón vital que supuso para Campoamor su exilio forzoso queda reflejado en el título de la obra teatral objeto del presente análisis, el cual resulta de una adaptación de Con las raíces cortadas, título del proyecto autobiográfico que Campoamor no pudo llegar a acometer. Como advierte Adolfo Sánchez Vázquez, «a

${ }^{15}$ Entre las personas pertenecientes a la tercera España, Preston señala a Salvador de Madariaga, Manuel Portela Valladares, Joan Baptista Roca i Caball, Manuel Carrasco i Formiguera, Mateo Múgica y Urrestarazu, Luis Lucia, Julián Besteiro y José Ortega y Gasset. 
ningún exiliado puede compensar... lo que ha perdido al abandonar su suelo» (2003: 569). Y sin embargo, como se incide en la obra teatral, los exilios de sus protagonistas no resultan parangonables.

En el caso de Campoamor, como informa Samblancat Miranda, la desgarradura que seguramente le ocasionaría su desengaño político resultó acicate para su partida el 28 de agosto de 1936 (2002: 46). Primero se dirigiría a Suiza, trasladándose posteriormente a Argentina. Según Fagoaga y Saavedra, Campoamor llega a Buenos Aires en 1938, en donde permanecerá hasta 1955. Allí ejercerá diversos trabajos, algunos de índole cultural y otros relacionados con la abogacía. Con la dictadura del General Perón se traslada a Lausana, donde residirá hasta su fallecimiento en 1972. Tras haber intentado infructuosamente durante varias ocasiones volver a España- en 1948, 1952 y 1955 - se cumplirá su última voluntad de ver trasladados sus restos al cementerio de San Sebastián.

Sin embargo, Kent tuvo una experiencia del exilio diferente. Éste se inició estando ella destinada en la Embajada española en París. Allí, debido a su dedicación a causas humanitarias, demoró tanto su salida a Méjico que tuvo que vivir en la clandestinidad hasta la liberación de París. Posteriormente, residiría en Méjico de 1948 a 1950, año en el que se instala en Estados Unidos, donde viviría hasta el final de sus días. Inicialmente fue allí para trabajar para las Naciones Unidas. En Nueva York conocería a Louise Crane, acaudalada hispanista, con quien inició una relación laboral —que se materializaría, entre otros proyectos, en la fundación de la revista Ibérica - y sentimental que le permitió echar nuevas raíces. Como indican unas notas redactadas a modo de testamento, a Crane le debe la tranquilidad y el bienestar moral y material durante su última etapa de vida. Utilizando la terminología de Vicente Gaos, sería durante esta etapa que Kent llegaría en cierto modo a «transterrarse». Además, tuvo la fortuna de sobrevivir al fin del franquismo, llegando a visitar España en 1977 y en 1978. Lo volvería a intentar posteriormente, pero su delicada salud se lo impediría, muriendo en 1987 en Nueva York de un paro cardíaco.

\section{PERSONAJES DRAMÁTICOS AL SERVICIO DE LA REFLEXIÓN HISTÓRICA}

El análisis crítico que subyace a lo largo de Las raíces cortadas del pasado vivido por las protagonistas se ve acrecentado en virtud del receptor de la obra, quien recrea igualmente los sucesos representados a la luz del mo- 
mento presente. Tal lectura de los hechos añade un plano de significación adicional a la obra. En este sentido, para exacerbar el carácter de reflexión en el caso de la controversia creada por el debate parlamentario en torno al sufragio femenino, la obra recurre al metateatro. Aparece en escena un teatrito de marionetas, en el que el carácter de farsa del debate adquiere tintes grotescos. La ridiculización hasta el paroxismo de la rivalidad asumida en su momento por Campoamor y Kent en un tema que les afectaba por igual expele una misoginia irrefutable por parte de sus colegas masculinos. Convertidas en títeres incapaces de cederse la palabra, recibirán el apelativo despectivo de «la Clara» (Campoamor) y «la Yema» (Kent) por parte de «el Atildado Presidente Don Julián», títere que representa a Julián Besteiro, Presidente del Congreso de Diputados tras las elecciones del $31^{16}$. Éste no sólo cosifica a Campoamor y a Kent, al designarlas como partes del huevo, sino que incluso las animaliza, al observar que «cacarean» (2005: 61). Llega incluso a prohibir a Kent que gesticule durante su intervención, caricaturizando cómicamente sus movimientos. Consumando nuevamente su menosprecio sexista, ante la protesta de ambas diputadas, el títere Don Julián amenaza con hacer con ellas una tortilla. Sin duda, las connotaciones implicadas al asimilar a las dos mujeres con partes del huevo, junto con las evocaciones relativas a la orientación sexual del término «tortilla», apuntan a un intento de descalificación por parte de Don Julián de ambas mujeres en base a una insinuada homosexualidad. Tales imputaciones se verán refrendadas por el títere Santo Mandilón, quien afirma: «Son marimachos, trasgos al servicio del mismísimo diablo» (2005: 62). De este modo, queda confirmada en la obra la observación de Shirley Mangini acerca de la percepción de Campoamor y Kent por sus colegas masculinos: «desde Azaña hasta los intelectuales más «liberales»... las disputadas eran sospechosamente viriles, e incluso aberrantes» (2001: 200). Para culminar la misoginia de la escena, reflejo del inveterado patriarcado entonces imperante, los comentarios del títere Diputado Jeremías expresan las expectativas de la época sobre el futuro de la mujer: «iLas faldas mandando en España!... iSomos unos calzonazos! ¡Las mujeres a sus casas, a servir a sus maridos!» (2005: 62), o «[s]i quieren ser útiles, lo que tienen que hacer, en lugar de votar, es parir hijos republicanos» (2005: 63) ${ }^{17}$. El espíritu crítico subyacente al regodeo sexista

16 Julián Besteiro era partidario de la no concesión del voto femenino (Gutiérrez Vega, 2001: 74).

17 Juan Ferragut, periodista del Mundo Gráfico, escribiría el 7 de julio de 1931: «En el Congreso no hubieran estado mal un par de mujeres de su casa. Y sin que esto sea una censura para el celibato de las dos diputadas actuales, digamos que las hubiéramos preferido casadas. Y, además de casadas, con unos cuantos hijos» (cit. en Rodrigo, 1988: 86). 
que emana de toda la escena resulta obvio debido al tono satírico y al tratamiento esperpéntico.

El carácter de farsa se retomará en el último acto de la obra, el cual tiene lugar en un hospital en Nueva York en 1987. Victoria Kent, postrada en una silla de ruedas, conjura con su recuerdo a Clara Campoamor, quien acude a visitarla. Al enseñarle las marionetas de ellas como diputadas, Kent le pregunta si se reconoce en semejante esperpento. En ese momento parece establecerse cierta complicidad entre ambas al admitir que bien se reían de ellas el resto de la clase política: «Nuestros rifirrafes parlamentarios fueron motivos de burla para sus señorías. Nos tomaban a chacota» (84). Es más, Kent recuerda a Campoamor las palabras de Azaña en relación con su cese como Directora General de Prisiones: «En el Consejo de Ministros hemos logrado por fin ejecutar a Victoria Kent [...] Ha fracasado. Demasiado humanitaria y pocas dotes de mando» (1978: 84).

Tal constatación le lleva a Kent a afirmar como balance de sus vidas: «Reconozcamos que somos dos perdedoras» (85). La crudeza del pesimismo que encierra tamaña afirmación queda aquilatada cuando Campoamor espeta: «¿Quién podría imaginarse que la combativa Victoria Kent, la que se ha hartado de decir que lo bello es luchar por una noble causa, no creía en sus propias palabras?» (2005: 85). Sin embargo, tras la catarsis realizada mediante el doloroso buceo por el pasado, Campoamor termina compartiendo el balance pesimista de Kent. La sororidad entre ellas parece finalmente aflorar, mientras Kent descuartiza impasible su marioneta de diputada. En este sentido, en la obra el papel político tanto de Campoamor como de Kent recoge una catástrofe personal.

No obstante, no se baja el telón con un balance negativo de la vida de estas dos mujeres. A pesar de haber mostrado las frustraciones sufridas por Campoamor y Kent, se resalta la importancia de recordar sin amargura ni sentimiento de fracaso, tal como manifiestan las siguientes palabras de Campoamor en el momento de acabar la obra: «[E]l fracaso está en que rememoremos aquellos hechos con amargura. [...] Trabajamos para el futuro, aunque no lleguemos a verlo» (2005: 92). Dichas palabras se verán refrendadas por la escena que recoge las acotaciones teatrales que figuran como final de la representación: Campoamor y Kent, con las manos enlazadas, se proyectan sobre una playa desierta, la cual se va poblando de figuras que van dejando sus huellas sobre la arena, para desaparecer ambas con el incesante devenir de las olas. Junto a conocidos sujetos históricos -Margarita Nelken, Dolores Ibárruri, Federica Montseny, Alfonso Manuel Rodríguez Castelao, 
Francisco Largo Caballero, o Fernando de los Ríos- desfilan figuras anónimas, como aquel miliciano con el fúsil en alto, captado por la cámara de Robert Capa en el momento de ser abatido al saltar la trinchera.

Ciertamente, el punto de reflexión desde las circunstancias presentes será, a la postre, el que acabe imponiéndose, mediante una unificación de todos los tiempos: el histórico, el de la conciencia personal de las protagonista y el momento presente. De ahí que mi parecer coincida con la apreciación de John P. Gabriele, quien afirma que López Mozo aspira a «enaltecer la conciencia de su público» con su teatro, mediante una «perspectiva de reflexión intelectual deliberada» a partir de una implicación emocional del espectador (2004: 129).

Gracias a la reflexión inducida por Las raíces cortadas esa Memoria Histórica reclamada tan en boga recupera las memorias de unas mujeres adelantadas a su tiempo, de convicciones profundas e independencia probada. Al mismo tiempo, la mencionada reflexión constata la paradoja de cómo los antagonismos cobran mayor dimensión cuanto mayores son las semejanzas. Tal es el caso de Campoamor y Kent, cuyas trayectorias personales y profesionales plagadas de semejanzas acrecentaron la dimensión de sus diferencias. Es por ello que la sororidad que finalmente aflora en la representación contribuye a una perspectiva histórica que resalta la necesidad de reflexionar críticamente sobre el pasado para poder avanzar en el futuro. Es ahí donde radica su reto a la memoria dominante.

\section{REFERENCIAS BIBLIOGRÁFICAS}

ALBORCH, Carmen (2007). «Prólogo». En Victoria Kent: Una pasión republicana, de Miguel Ángel Villena, 11-32. Barcelona: Debate.

AZAÑA, Manuel (1978). Memorias políticas y de guerra, vol 1. Barcelona: Critica.

CAMPAL, José Luis (2007). «López Mozo dramatiza el 11-S». La Ratonera. Revista asturiana de teatro 19, enero. http://www.la-ratonera. net/numero19/n19 mozo.html.

CAMPOAMOR, Clara (1981). Mi pecado mortal: El voto femenino y yo. Barcelona: LaSal, Edicions de les Dones.

- (2002). La revolución española vista por una republicana. Trad. Eugenia Quereda Belmonte. Bellaterra: Universitat Autonòma de Barcelona, Servei de Publicacions. 
CAPEL MARTÍNEZ, Rosa María (1992). El sufragio femenino en la Segunda Republica española. Madrid: Horas y Horas / Direccion General de la Mujer / Comunidad de Madrid.

FAGOAGA, Concha (1985). La voz y el voto de las mujeres: El sufragismo en España 1877-1931. Barcelona: Icaria.

FAGOAGA, Concha y SAAVEDRA, Paloma (1981). Clara Campoamor, la sufragista española. Madrid: Direccion General de Juventud y Promocion Socio-cultural / Subdireccion General de la Mujer.

FLOECK, Wilfried (2006). «Del drama histórico al teatro de la memoria. Lucha entre el olvido y búsqueda de identidad en el teatro español reciente». En Tendencias escénicas a principios del siglo XXI, José Romera Castillo (ed.), 185-209. Madrid: Visor Libros.

«Las Cortes Generales aprueban definitivamente la ley de Memoria Histórica» (2007). El País.com, 10 de diciembre.

http://www.elpais.com/articulo/espana/Cortes/Generales/aprueban /definitivamente/ley/Memoria/Historicalelpepuesp/20071210elpepunac_16/Tes.

GABRIELE, John P. (2004). «Forma y función de un teatro documental español: “Ahlán”, de Jerónimo López Mozo». En Teatro y sociedad en la España actual, Wilfried Floeck y María Francisca Vilches de Frutos (eds.), 129-37. Madrid: Iberoamericana.

GUTIÉRREZ VEGA, Zenaida (2001). Victoria Kent: Una vida al servicio del humanismo liberal. Málaga: Servicio de Publicaciones de la Universidad de Málaga.

IRIGARAY, Luce (1985). This Sex Which Is Not One. Ithaca, N.Y.: Cornell University Press.

LÓPEZ MOZO, Jerónimo (1999a). «Despojamiento y realismo en mi último teatro». En Entre actos: Diálogos sobre teatro español entre siglos, Martha T. Halsey y Phyllis Zatlin (eds.), 31-41. University Park (Pennsylvania): Estreno.

- (1999b). «El "Nuevo Teatro Español" durante la Transición: Una llama viva». En Entre actos: Diálogos sobre teatro español entre siglos, Martha T. Halsey y Phyllis Zatlin (eds.), 17-22. University Park (Pennsylvania): Estreno.

- (2005). Las raíces cortadas. Madrid: Asociación de Autores de Teatro y Consejería de Cultura de la Comunidad de Madrid. 
MANGINI, Shirley (2001). Las modernas de Madrid: Las grandes intelectuales españolas de la vanguardia. Barcelona: Ediciones Península.

NASH, Mary (1999). Rojas: Las mujeres republicanas en la Guerra Civil. Trad. Irene Cifuentes. Madrid: Taurus.

PRESTON, Paul (2003). Las tres Españas del 36. Barcelona: Random House Mondadori.

RODRIGO, Antonina (1988). Mujeres de España: Las silenciadas. Barcelona: Círculo de Lectores.

ROMERA CASTILLO, José (2000). «Prólogo». En Combate de ciegos. Yo maldita india... (dos obras de teatro), Jerónimo López Mozo, 9-24. Madrid: Universidad Nacional de Educación a Distancia. http://www.uned.es/centro-investigacion-SELITEN@T/pdf/blmozo.pdf.

SAMBLANCAT MIRANDA, Neus (2000). «La revolucion espanola vista por una republicana: Clara Campoamor o la lucidez de una luchadora». En Las literaturas del exilio republicano de 1932: Actas del II Congreso Internacional (Bellaterra 1999), vol 2, Manuel Aznar Soler (ed.), 121-32. Barcelona: Associacio d'Idees y GEXEL.

- (2002). Estudio introductorio, edicion y notas, 13-61. La revolución española vista por una republicana, de Clara Campoamor. Trad. Eugenia Quereda Belmonte. Bellaterra: Universitat Autonoma de Barcelona, Servei de Publicacions.

SÁNCHEZ VÁZQUEZ, Adolfo (2003). A tiempo y destiempo: Antología de ensayos. Mexico D.F.: Fondo de Cultura Economica.

TELO NÚÑEZ, María (1995). Concepción Arenal y Victoria Kent: Las prisiones, vida y obra. Madrid: Instituto de la Mujer.

VILLENA, Miguel Ángel (2007). Victoria Kent: Una pasión republicana. Barcelona: Debate.

«Zapatero quiere sacar la Ley de Memoria Histórica antes del fin de la legislatura» (2007). El País.com 8 sep:

http://www.elpais.com/articulo/espanaZapatero/quiere/sacar/Ley/ Memorial/Historicalfin/legislatura/elpepuesp/20070908elpepunac_5/Tes. 